\title{
La lógica del lenguaje y sus estrategias para otorgar identidades
}

\section{The Logic of Language and it's Strategies for Granting Identities}

\author{
Heinrich Helberg Chávez \\ Universidad Nacional de la Amazonía Peruana \\ hhelberg@hotmail.com \\ https://orcid.org/oooo-0oo1-6417-0373
}

A la memoria de Jorge Alberto Che Piu Salazar

\begin{abstract}
Resumen
Este trabajo trata de los problemas lógicos y filosóficos de la lógica del lenguaje cotidiano. Lo hacemos en el marco de una visión del lenguaje como una práctica social que se sostiene a sí misma.

La identidad de las cosas no aparece objetivada como una esencia recóndita que da identidad a pesar de la apariencia diversa, sino como una práctica social que confiere identidad de acuerdo a los juicios y razones que aducen los hablantes al momento de hablar, basados en sus conocimientos cotidianos y su forma de vida, y otros conocimientos que sirven de marco de referencia inmediato. Este planteamiento permite además echar una luz diferente a los problemas filosóficos clásicos como los que plantea la filosofía de Heráclito.
\end{abstract}

Palabras clave: filosofía de lenguaje, gramática, lógica del lenguaje cotidiano, adquisición de lenguaje, problemas filosóficos, Heráclito

\begin{abstract}
This work deals with the logical and philosophical problems of everyday language logic. We do this within the framework of a vision of language as a social practice that sustains itself.

The identity of things is not objective as a secluded essence that gives identity despite the diverse appearance, but as a social practice that confers identity according to the judgments and reasons that speakers argue when they speak, based on their daily knowledge and way of life, which serve as a framework of immediate reference. This approach also allows to shed a different light on classical philosophical problems such as those posed by The Philosophy of Heráclito.
\end{abstract}

keywords: philosophy of language, grammar, everyday language logic, language acquisition, philosophical problems, Heraclit 


\section{Introducción: La lógica y los usos del lenguaje cotidiano}

Este trabajo trata de los problemas lógicos y filosóficos de la lógica del lenguaje cotidiano, teniendo como referencia una gramática como la presento en mi artículo Lingüistica del habla en líneas muy generales.

La lingüística del habla se entiende como una ciencia empírica que se orienta por los resultados de la lógica del lenguaje ordinario, o como prefiero llamarla lógica del lenguaje cotidiano. Y que contiene como uno de sus componentes la competencia de hacer inferencias y sacar conclusiones a la que Francisco Miró Quesada se refiere cuando afirmó:

Hay una lógica que es la que usamos cuando pensamos racionalmente de manera espontánea y ella es el fundamento en torno del cual se constituyen todas las lógicas, es la base sin la que ninguna lógica formal, por más aberrante que sea, tiene sentido. (F. Miró Quesada, 1982, III,1, pp. 3 y 13-16)

Y es lo que se entiende como lógica del sentido común, o como lógica natural o lógica folk, que es el conocimiento que maneja el hablante para hacer sus propias deducciones lógicas. Se trata de un saber previo a toda construcción teórica, previo a la ciencia de la lógica y la lingüística. Pero que tiene el interés de ser el conocimiento constitutivo del lenguaje, con el que el lenguaje funciona. Y todas las ciencias como la lingüística o la misma física, en la medida que piensan, también tienen ese conocimiento como fundamento, al que muchas veces tratan como un conocimiento no sistemático, limitado e inferior al científico. En mi trabajo, La lingüistica del habla [Helberg 2007], en cambio, no se acepta esto, y se adopta el punto de vista del discurso cotidiano, que se esclarece a sí mismo, sin pretensiones teóricas, sino más bien con propósitos prácticos, como, por ejemplo, entender otra cultura.

\subsection{La lógica del lenguaje cotidiano}

A ese conocimiento que nos permite hablar y no solo eso, sino actuar, está dirigido este estudio, pero con una noción ampliada de lógica, que no se refiere solo a las inferencias lógicas, sino a todo el conocimiento gramatical. Por eso entiendo por lógica del lenguaje cotidiano todo lo que tiene el carácter de regla en el lenguaje ordinario, no solo lo que se ha venido en llamar «lógica del lenguaje ordinario»

$38 \quad$ Lengua y Sociedad. Revista de Lingüística Teórica y Aplicada 
o «lógica natural» [Palau, 2014 p. 15] que se refiere solo o preponderantemente al sistema inferencial de las lenguas naturales. Este es el sentido ampliado que le da Wittgenstein en sus Investigaciones filosóficas.

Uso también el término «lógica del lenguaje» en un sentido más restrictivo para la secuencia de habilidades que se adquieren durante el proceso de socialización que culmina con el dominio del discurso cotidiano, que es una competencia comunicativa que nos toma unos 15 a 20 años adquirir, y que es seguro la tarea más compleja que afrontan los seres humanos y la que sienta las bases para su vida intelectual, emocional, la interacción social y con su medio.

\subsection{Las reglas del lenguaje son prácticas}

Las reglas del lenguaje pueden tomar formas muy distintas, no solo la de la generalización explícita que domina una serie de casos, que son los ejemplos de aplicación, sino también el ejemplo que sirve de modelo para otros ejemplos, la serie de ejemplos que define una regla [la definición extensiva], la definición ostentativa, señalando al objeto, la imitación, la conducta conducida, y otras que llevan a que se adopte un comportamiento regular. También sucede que el sustento de una unidad de sentido, pueda estar al revés de nuestra expectativa, es decir no normar para introducir un comportamiento regular, sino expresar la norma en una coincidencia estadística: coincidimos en que podemos reconocer un color, por ejemplo. Y sin esa coincidencia no se podría introducir a nadie a la dimensión del color.

Es la comunidad de sentido la que juzga qué es regular o qué se acepta y qué no, incluyendo la posibilidad de adaptar la norma a contextos y de innovar normas. Lo que hace que las prácticas sociales sean flexibles y que ocurran bajo el precepto general que los comportamientos y expresiones dan sentido. Y que los errores y sinsentidos son la excepción, por lo que nunca se trata de construir un sentido a partir de un conjunto de reglas cuyo producto sea ese sentido. Lo que tiene una consecuencia impredecible: la práctica del lenguaje no se deja reducir a un cálculo matemático. Porque requiere de la aceptación de la expresión en el mismo uso, esto es, en cada caso concreto.

Esto significa que el sentido válido no es solo producto de coincidencias entre lo que se dice y entiende, que podrían ser descritas con un cuerpo de reglas, similar a un cálculo, sino que los hablantes son personas, y que toman decisiones propias y que éstas muchas veces son previsibles porque el uso del lenguaje está 
La lógica del lenguaje y sus estrategias para otorgar identidades

Heinrich Helberg Chávez

institucionalizado, como dice Wittgenstein, pero no siempre se sigue el uso institucionalizado (Wittgenstein $2001 \$ 199$ ), como el mismo Wittgenstein lo demuestra con los usos filosóficos, y por eso los sentidos que les dan los hablantes a las expresiones no son calculables. Y eso tiene que ver con la adaptación a los contextos en que se encuentran, que permiten crear sentidos nuevos, y que, si los interlocutores aceptan, entonces valen como «entendidos», por lo menos para esa determinada situación. Y así se introduce la variación en el uso del lenguaje. El proceso de comprensión no es por lo tanto una mera aplicación de reglas, sino que implica una reinterpretación y extensión en el uso.

Una de las consecuencias es que entender no consiste en aplicar reglas o cotejar, sino que los hablantes pueden aceptar el uso específico como se da, es una opción, o iniciar un proceso de comprensión mutua, en el que van a comparar sentidos y para qué se usa la expresión, cómo está institucionalizada, discutir si el uso particular es aceptable. Verán también si el referente es el mismo, cuando viene al caso y cómo se define, según las estrategias de definición que les ofrece su lenguaje. Lo importante no es cerciorarse que actúan de acuerdo a las reglas establecidas, sino si aceptan los usos innovativos, y si lo hacen, entonces el uso establecido es solo un referente, un elemento más en el proceso de comprensión.

Como recordaremos Wittgenstein acepta las innovaciones cuando tienen un uso práctico y rechaza los usos disfuncionales (filosóficos) por inútiles (Wittgenstein $2001 \$ 132)$. Y esa distinción, si damos una mirada detallada a los usos del lenguaje cotidiano es válida para todos los usos.

En consecuencia, este uso de «lógica del lenguaje» trata de contenidos y de cómo se construye la experiencia humana, a la medida de la capacidad de interacción y comprensión de un niño que se socializa y se está introduciendo en un universo de lenguaje, con todos sus mecanismos, no reducibles a formalidades. Pero trata de un tipo de conocimientos cotidianos, muy distintos de los conocimientos a priori de Kant, como los explica en la Introducción de la segunda edición de la Crítica de la razón pura. Con los cuales hay una correlación sin embargo, porque los niños son introducidos primero al tiempo y el espacio sin medidas y a la causalidad de forma práctica, y más todavía, hay esa correlación con los conocimientos teóricos de la lógica de Hegel, por ejemplo, o de las categorías que define Aristóteles 1978 en su Metafísica y entonces salta a la vista las diferencias entre el marco de referencia teórico y el práctico, que es parte de la experiencia aunque tiene funciones lógicas. Pero en este caso no se trata de conocimientos a priori, ni de conocimientos teóricos, ni de categorías, sino de conocimientos 
cotidianos, que se adquieren de forma práctica y son parte de la visión cotidiana de la vida. Y nunca se introduce al niño directamente en el uso del tiempo y el espacio, de la secuencia temporal, de la causalidad cercana y a la lejana, de que si gritas a alguien capaz se enferma, y de eso se ocupa Wittgenstein en Sobre la Certeza. Donde trabaja la arquitectura lógica de las culturas (Wittgenstein 1970). Estas nociones fundamentales se aprenden como parte de otros usos y funcionan como supuestos que se deducen del todo, no de una introducción específica, en la que se explique la causalidad o las relaciones sico-somáticas, eso no se da.

El propósito de los filósofos de llegar a un conocimiento explícito de los fundamentos de la cultura y vida social contraviene la arquitectura interna de una cultura que sigue una lógica práctica, que transmite los ejemplos que explicitan la regla, pero no la regla.

Y de allí deviene la dificultad de definir el tiempo, la causalidad, la esencia y todas esas categorías que la filosofía ha considerado fundamentales, porque el contenido de esas nociones que nos da el lenguaje es práctico. Se sustentan en una introducción práctica. Y no es racional quererlas explicar con razones explícitas, porque eso contraviene su naturaleza práctica y lo único que producimos son racionalizaciones, en lugar de aceptar que hay una lógica práctica, que hay que describir en sus propios términos.

\section{Cambio de visión de lenguaje}

Este desarrollo de la lógica implica un cambio de visión del lenguaje, de un conjunto de nombres para referirse al mundo, una visión cognitiva muy típica del pensamiento occidental, a una competencia comunicativa, que se caracteriza por una serie de habilidades sociales como pactar unidades de sentido, reconocer regularidades y generar nuevas unidades de sentido, saber usar unidades sintácticas y variarlas y adecuarlas a contextos, adquirir la alteridad, saber ubicarse en la estructura de diálogo, interactuar con el mundo fáctico, pero también con posibilidades, probabilidades y usar de la imaginación y de la fantasía, manejar distintos sistemas de ubicación espacial y temporal simultáneos, desarrollar lazos afectivos, con objetos, animales y personas, saber apreciar situaciones de manera holística, ubicarse en ellas y desarrollar una o más interpretaciones de las situaciones en que vivimos.

Lo que le permite a los niños que empiezan a usar su lenguaje, saber en qué discurso ubicarse, encontrar su rol y definir cómo pueden intervenir. 
Y en cierta etapa empiezan a argumentar y preguntar el porqué de todo. Aún en los pueblos aislados de la Amazonía saben que los niños pasan por una etapa que llamamos «la edad de la razón» en la que preguntan por todo. Y es así como los padres siguen el desarrollo de sus niños, por hitos que van cumpliendo.

De manera que hay un conocimiento de los padres que les permite medir el avance de sus niños por hitos, y este conocimiento es parte del proceso, que no puede formularse sin su participación, porque no hay interacción social sin acuerdos sociales y sin unidades de sentido que responden a intenciones, esto es sin fines.

Si como sucede a veces en las descripciones de corte científico, se aísla al niño de los padres y se le trata como "objeto de estudio», al que se confronta con preguntas y situaciones nuevas, de laboratorio, para ver cómo responde, ya se distorsionó el proceso, porque el conocimiento de los padres es parte de él, ya que son los padres y el consenso social general los que aceptan o no las unidades de sentido que proponga el niño, aceptan o no las expresiones y las razones que las sustentan, porque el mundo de sentido es colectivo. Y si bien los niños construyen sus propios lenguajes, éstos están en interacción constante con el universo social establecido. Y los padres tienen que deducir el sentido de las expresiones de sus niños de toda la situación, no solo de las expresiones verbales. Y esta es una constante del uso del lenguaje.

$\mathrm{Y}$ los padres no solo asignan significados a las expresiones de sus niños, sino también emociones y entran en interacciones, de manera que la comprensión se da siempre en varios niveles simultáneos. Esta multiplicidad de sentidos simultáneos no ha sido observada por la lingüística, que ha seguido la tradición de pensamiento occidental y se ha interesado más por el lado cognitivo del lenguaje, y eso no le permite describir prácticas y discursos que son más emocionales o interactivos. Porque no ha trabajado la comprensión emocional y su dinámica.

La característica principal de todo este proceso de adquisición de lenguaje es que las habilidades lógicas y comunicativas se adquieren indirectamente, a través de interacciones y juegos, como jugar a preparar comida sin ingredientes o hablar y desarrollar relaciones emocionales con juguetes o ubicarse en el espacio y el tiempo, escondiéndose bajo la cama, tapándose con la frazada, o apurándose a comer, antes que el hermano mayor le quite el dulce. Y lo mismo es con las unidades sintácticas, se adaptan frases hechas a nuevas situaciones, sin nunca gramaticalizar o formular reglas. Un principio que Mark Aronoff usó en su 
morfología: nunca presentar un análisis que no de sentido en una posible situación de uso concreta.

Y esto no se debe a ninguna deficiencia, sino a que se está usando la lógica práctica. Y pretender hacer todo explícito, como lo quieren hacer los filósofos con las categorías fundamentales, distorsiona el proceso, no lleva a reconocer la realidad como es, sino a racionalizar, a inventarse una razón (teórica) que no aplica, en lugar de describir la razón práctica. Y eso es lo que ha caracterizado al pensamiento occidental, tanto en su filosofía como en las ciencias. Por eso es que, como alternativa, buscamos explicaciones con modelos prácticos.

Las habilidades indicadas arriba ya las tienen los niños a los 4-5 años, edad en que de pronto pueden referirse a su propio lenguaje, y ya no solo lo usan de manera funcional, con sentidos contextualizados, sino que pueden preguntar por el sentido de las palabras y ese es el uso literal del lenguaje. Y que también pueden preguntar por los supuestos, que deducen del todo. Dicen, por ejemplo, que la sombra les nace de los pies. O que la luna los sigue a todas partes.

Los supuestos no son conocimientos adquiridos individualmente, son parte del marco de referencia de una comunidad de sentido. Por eso cuando el niño o niña descubre esos supuestos no se trata de un conocimiento que corrobora individualmente, sino que esas experiencias, las explica la comunidad, ella confirma o no, que el sol no camina debajo de la tierra por la noche. El niño solo no puede adquirir ese tipo de conocimiento, porque requiere de la experiencia acumulada de muchas generaciones y de una cosmovisión organizada.

\section{La lógica formal como ciencia del pensamiento}

Lo interesante es que en la cultura occidental se ha trabajado con mucho esfuerzo y rigor lo que se conoce como la lógica formal, desde que Aristóteles trabajó su primera versión, allá por el 400 antes de Cristo y que se mantuvo como cuerpo de conocimiento casi definitivo hasta que fue formalizada por la lógica proposicional a principios del siglo $\mathrm{xx}$, y luego ampliada para ir incorporando posibilidades y probabilidades y acercando así este modelo a las complejidades de la lógica del lenguaje cotidiano.

La definición de los manuales de lógica como una disciplina que trata de las reglas del pensamiento correcto es muy amplia, porque la lógica propositiva se ocupa solo de un conjunto de habilidades inferenciales. Explicar qué es el 
La lógica del lenguaje y sus estrategias para otorgar identidades

Heinrich Helberg Chávez

pensamiento y qué roles juega en la vida humana es un tema mucho más amplio que a veces se ha asignado a la psicología. Pero la psicología tampoco tiene las respuestas. Porque llegar a una respuesta supone un conocimiento profundo de lo que se llama pensar y eso no tenemos. Solo tenemos una enseñanza acerca de cómo hacer inferencias lógicas que tiene muchas deficiencias de modelo, si se le compara con lo que sabemos entretanto de «saber hablar» y dentro del dominio del habla, saber eso que se llama pensar.

Pensar incluye muchas habilidades como identificar objetos, personas, acciones, situaciones y todo de lo que hablamos, descubrir regularidades, formular reglas para esas regularidades, sintetizar, dudar, explicar, ordenar, argumentar, justificar con razones, sacar conclusiones, encontrar supuestos, entender situaciones, reaccionar apropiadamente a ellas, encontrar razones para tomar decisiones y varios más.

\section{Emociones y razones}

Las emociones también obedecen a razones y los miedos pueden ser racionales o irracionales si no obedecen a razones o las razones no aplican. Pero obviamente también se llama pensar al encontrar razones aparentes que esconden las verdaderas (las que son inconfesables) y entonces se produce justificaciones racionales, donde en realidad no caben y por eso hablamos de racionalizaciones.

Y todas estas habilidades llevan al descubrimiento de criterios de uso concretos, constatables en la experiencia cotidiana. Por ejemplo, recordamos algo, y lo decimos, y la verdad de lo que decimos es constatable, y así se decide si recordamos o no, si estamos inventando o estamos confundidos y decimos lo que no recordamos. Porque creer que recordamos y recordar no es lo mismo.

\section{La lógica proposicional}

Cabe decir que la lógica proposicional «conecta ideas/proposiciones por medio de conectores lógicos para llegar a conclusiones», así dice «si, a y b, entonces $c$ », pero se deja de lado que el sentido de las ideas/proposiciones solo se define en situaciones/usos concretos, y que esos usos se dan en culturas, que actúan como supuestos. Y que, por lo tanto, el modelo es reduccionista e insuficiente, al no considerar las condiciones efectivas para definir los sentidos de las proposiciones y sus interconexiones, como el contexto particular o los supuestos (y que hay una

$44 \quad$ Lengua y Sociedad. Revista de Lingüística Teórica y Aplicada 
jerarquía de ellos). Lo que da cuenta de las dificultades de aplicación de las «tablas de verdad», porque el modelo está muy alejado de los usos reales.

Debemos preguntarnos: ¿Tenemos todos los conectores lógicos? Posiblemente no: faltan al menos, los restrictivos, como «pero» $\mathrm{y}$ «sin embargo».

Necesitamos conocer las razones que motivan los juicios, pero las razones no aparecen por ningún lado. Entonces habría que introducirlas, porque sin argumentos los juicios no se sustentan.

Efectivamente resulta muy extraño, que en la lógica que dice promover el uso de la razón, las razones no aparezcan por ningún lado.

Ahora bien, el modelo calcula los valores de verdad por un simple cálculo de posibilidades y asigna ciertos valores a las variables «a y b», por ejemplo, que pueden ser:

\begin{tabular}{|cc|}
\hline $\mathrm{v}$ & $\mathrm{v}$ \\
\hline $\mathrm{f}$ & $\mathrm{v}$ \\
\hline $\mathrm{v}$ & $\mathrm{f}$ \\
\hline $\mathrm{f}$ & $\mathrm{f}$ \\
\hline
\end{tabular}

Sucede que este cálculo de posibilidades está descontextualizado y por eso parece depender solo de los conectores lógicos, pero en realidad depende de muchos supuestos. Lo cierto es que el sentido y la identidad de los referentes depende de los juicios cotidianos sobre ellos, es decir, de esa lógica práctica del lenguaje cotidiano, de esa que había sido dejada de lado por inexacta para introducir una notación más exacta de las ideas, y que es la lógica del sentido común, y que usa de ciertos criterios controlables en la práctica del habla cotidiana para definir los sentidos.

Ese es uno de los aportes del pensamiento tardío de Ludwig Wittgenstein, el haber demostrado, que hay una gramática profunda (Wittgenstein 2001\$664) que gestiona una enorme cantidad de criterios de uso (Wittgenstein 2001 \$269) para definir los sentidos en juicios prácticos, y que supera sus ingenuidades iniciales con las tablas de verdad que introdujo en el Tractatus.

El mundo de las posibilidades lógicas no se puede definir sin el mundo de lo fáctico, porque las posibilidades se deducen de la forma cómo tenemos experiencia del mundo. Es decir, la estructura de lo que pensamos, las maneras como enjuiciamos la realidad subyace a todo lo que hablamos, y obviamente también a todas las deducciones. 
La lógica del lenguaje y sus estrategias para otorgar identidades

Heinrich Helberg Chávez

Y lo interesante es que como los hablantes generalmente actúan con fines prácticos, y no acuden a teorías, a un marco de referencia contemplativo, pues usan juicios prácticos. Que tienen una lógica totalmente distinta, pues no se justifican por el conocimiento de la realidad, ni las predicciones ni modelos científicos, sino por motivos prácticos como el miedo, las emociones, los fines personales, los intereses, etc.

En consecuencia, la lógica proposicional nos ha dado una imagen sesgada de la realidad, como si se tratara siempre de una gestión racional de la realidad, como característica humana, cuando en realidad esa imagen no se ajusta a la verdad para una enorme cantidad de casos. Esto quiere decir que tenemos varias opciones, que podemos pensar, dudar, sacar conclusiones y tomar decisiones, pero también podemos apostar por algo, o reaccionar, como nos han enseñado a reaccionar en ciertas situaciones, como ir en ayuda de alguien si grita y pide auxilio. Y eso no tiene nada de irracional.

Y eso es de lo más común, porque tenemos la opción de pensar y conocer, o también de creer, y en el primer caso tendremos argumentos y pruebas, y en el segundo no los tendremos. Y muchos argumentos se nos impondrán por necesidad lógica, pero a veces lo que parece ser necesidad lógica no lo es, solo estamos bajo presión psicológica, por la costumbre que se impone. Pidiendo explicaciones por pedir explicaciones, por puro formalismo, o imponiendo un esquema de explicación, cuando sabemos perfectamente que no aplica, pero insistimos por pura forma.

La diferencia entre saber y creer está en el uso de argumentos y pruebas cuando afirmamos que sabemos algo, mientras que si creemos, también lo afirmamos, pero sin recurrir a tales argumentos y pruebas, no los usamos. Y eso puede ocurrir porque desistimos de la discusión racional, como cuando apostamos por algo, por ejemplo, o porque lo que sostenemos es evidente, o parte del marco de referencia consensuado, o parte de las reglas de juego y no se cuestionan mientras se sigue el juego. En todo caso creer no supone mayor confianza o certeza, en los usos cotidianos, es una noción alterna al saber de algo, que se usa en situaciones distintas para otros objetivos. En los usos filosófico-teológicos, en cambio, puede sobrecargarse a las creencias con una certeza que quiere asimilar las asunciones religiosas a las creencias cotidianas del marco de referencia de la forma de vida cotidiana, que tienen el carácter de fundamentales y que por eso no se ponen en duda.

Generalmente actuamos por la costumbre, y solo si falla es que pensamos, dudamos, exploramos otras posibilidades y entonces entra otra lógica en acción,

$46 \quad$ Lengua y Sociedad. Revista de Lingüística Teórica y Aplicada 
para explicar el accionar humano, una lógica que tiene una aplicación más limitada, en algunos casos, que es el uso de la razón. Pero que, en la gran mayoría de otros casos, actuamos de acuerdo a la costumbre y la cultura, automáticamente, sin pensar ni dudar, porque así fuimos instruidos.

\section{La convivencia de las lógicas}

Si vemos cómo se aplican estas diferentes lógicas: las ciencias pretenden alcanzar conocimientos generales válidos; la medicina tradicional usa la lógica práctica; también compara y hace generalizaciones parciales y generales, justificándolas con condiciones particulares, no en estadísticas de casos (clasificaciones de particulares). La medicina académica se ocupa primordialmente de las causas [en laboratorio] y de los efectos en particulares en la fase de experimentación, primero en animales, luego en humanos. La medicina tradicional se ocupa casi exclusivamente de los efectos y no tiene medios de conocer más de cerca las causas.

El arte sigue más la lógica práctica, aunque ciertos autores desarrollan capacidad de deducción teórica. Y toman decisiones artísticas basados en su capacidad deductiva, donde los otros se dejan asombrar los efectos que han descubierto es su práctica.

Las generalizaciones totales permiten cierto control de la situación, diseñar políticas generales, por ejemplo, pero si surgen, durante una epidemia unos casos especiales, cuyo origen puede ser distinto al de los primeros, entonces este segundo grupo no conviene asimilarlo al primero, diluirlo en la generalización vasta, porque podrían tomarse medidas específicas mejor adaptadas a su caso. Detrás de una estadística hay razones que hay que ir a buscarlas en los casos particulares que condicionan comportamientos y efectos y que son las historias particulares, mientras que la estadística es ciega y no ofrece explicación para los resultados. De manera que queda claro que la estadística general de casos tiene un uso también general, pero que los conocimientos particulares, en su especificidad, pueden ayudar a solucionar el problema mejor y a entender qué pasa, porque esa mayoría está conformada de subgrupos, cada uno con su propia racionalidad. Y puede haber distintos subgrupos, sea por la manera de contagiarse, cómo reaccionan a la infección y qué respuesta tienen frente a los medicamentos. Y solo el que entiende tanto la caracterización general como las específicas tendrá una comprensión más cabal del asunto. Y muchas veces bastan las específicas, porque siempre actuamos sobre realidades particulares y es a ellas a las que hay que entender finalmente. 
Las generalizaciones vastas son parte de la interpretación de fenómenos particulares, ponen el marco general, pero entender no consiste en reducir lo particular a lo general, como puede pensarse, sino en descubrir la lógica de lo particular: cómo funciona. Y si ya conozco todos los detalles, para qué necesito las generalizaciones, se pregunta Wittgenstein, apuntando a que es innecesario. De manera que Wittgenstein aporta con una nueva manera de dar explicaciones: descubrir la lógica de particulares.

Pero pueda que sí haya propósitos en los que sí se necesita de generalizaciones, como para tratar de epidemias supranacionales, que exigen medidas distintas, que tratar un paciente particular. Queda establecido que tratar casos particulares sigue una lógica propia, que no se disuelve en generalidades. Y entonces conocer no es disolver lo concreto en abstracciones y generalidades, como proponen Hegel y Marx, sino entender lógicas particulares, algo que, para la academia, recién hace Wittgenstein en su filosofía tardía.

Lo que significa que la interacción de las lógicas es necesaria, pero que las ciencias se han especializado unilateralmente en los conocimientos generales. Y que felizmente los científicos acuden a su sentido común y superan individualmente esas deficiencias.

\section{La segunda gran decisión histórica es que:}

Los grandes excluidos de esta decisión cultural de favorecer los conocimientos generales como método de interpretación de la realidad son el sentido común, las culturas de pueblos que apostaron por transmitir sus culturas de forma práctica y las artes. Y esto porque se asimila el uso de la razón con el uso de generalizaciones totales. Cuando es bastante obvio que el uso de razones, causas, motivos, justificaciones, descripciones-modelo en el lenguaje cotidiano sigue reglas más refinadas y específicas que no convierten en irracional al seguir la costumbre, ni al actuar por emociones o intereses propios, ajenos o colectivos. Todo depende de las razones que tengamos o no tengamos para ello. Y no solo de las que podamos aducir, sino de las que se pueden aducir. 


\section{Las ciencias y la crítica del lenguaje cotidiano}

Conocido es, que en la etapa inicial de desarrollo de las ciencias se criticó al lenguaje cotidiano que era inexacto e impreciso, y el argumento principal era la polisemia. Injustamente a mi entender, porque la polisemia se da solo cuando se aísla las palabras de su uso contextual, porque se cree que las palabras tienen un sentido propio, de ellas, sin caer en cuenta que son los personas las que en su uso y con sus fines, son las que les dan sentido. Y en el uso concreto no se dan confusiones de sentido, justamente porque el contexto decide, y se necesita de una apreciación de la situación y del discurso para saber de qué se habla y poder darle sentido a las palabras.

Decir que «el caminante vino a tomarse su copa de vino» está totalmente claro y no contiene ninguna confusión posible en el uso concreto. Pero si sacamos las palabras de su contexto, las apuntamos, dos veces «vino», en una lista en el papel y luego queremos relacionar nombres con objetos (referentes), vamos a estar perdidos y peor si queremos construir la gramática como si las palabras fueran nombres, entonces sí que se dan ambivalencias, pero el problema está en la descontextualización, primero, en la creencia falsa que las palabras tienen un sentido propio de ellas, y luego en la concepción del lenguaje solo como un código de nombres y en el desconocimiento de cómo funciona en realidad.

Las ciencias se decidieron por crear lenguajes artificiales y el primero fue la mecánica, con una terminología científica basada en definiciones verbales, que pone Newton todas en un capítulo aparte de su Mecánica, que, sin embargo, no explican totalmente la lógica que tienen los términos que toman prestados del lenguaje cotidiano y generalmente permanecen dependientes de las nociones, los razonamientos y estrategias de argumentación prestadas del lenguaje cotidiano. Solo innovan a nivel lexical, pero al no haber basado su nueva comprensión en una evaluación de la experiencia y cómo el lenguaje con sus criterios cotidianos contribuye a la conformación de la experiencia, los problemas que surgen en ese propósito de hacerse una noción de la experiencia, se trasladan irreconocidos a los conceptos del lenguaje científico y entonces las definiciones nuevas suelen tener los mismos problemas de comprensión de la realidad que los usos cotidianos.

Por ejemplo, los usos científicos siguen creyendo que las emociones son sensaciones internas. O que la imaginación se debe a una visión interna. A veces se reconocen las metáforas, como la gran metáfora de los fenómenos internos/externos y nos damos cuenta que cuando amamos de todo corazón no ocurre nada en el 
órgano del corazón, pero no se puede corregir la metáfora por un lenguaje descriptivo, porque no se entiende el uso de las expresiones coloquiales en sus contextos, que justamente siguen una lógica práctica. Y no se tiene una visión general de los recursos del lenguaje cotidiano. El aislar los objetos de estudio se vuelve un problema metodológico para las ciencias.

La nueva terminología científica no suele resolver el problema de la comprensión de la lógica de la noción coloquial en cuestión, porque no se detectó ni analizó el problema. Se necesita otra estrategia que haga un análisis de la lógica de la noción y deslinde las reglas controlables y por ende socialmente válidas de las metáforas. Y esta es una situación precaria en que se encuentra la ciencia, y en esta situación ha vivido la ciencia confiando en sus definiciones verbales.

La filosofía del lenguaje reconstruye los usos de lenguaje en la práctica, ve que responden a acuerdos sociales muy distintos, según de qué se trate, y que la idea del lenguaje como sistema de nombres, es totalmente insuficiente como modelo: solo explica unos usos, pero no todos. Se ha sobre generalizado una hipótesis. Y las definiciones de las palabras quedan como abreviaturas, que explican lo necesario para el uso práctico, para entender de qué hablamos, pero tienen muchos supuestos sin explicar, si se quiere usar como modelo teórico del lenguaje. En buena cuenta, los hablantes coinciden en los usos y propósitos para los que sirven sus expresiones, más no en las definiciones. Entendemos por criterios de uso semántico, las razones que tienen los hablantes para las distinciones que hacen.

\section{Identificación de objetos y definición de sentidos}

Ahora, cómo se definen los sentidos de las palabras, pues siguen generalmente una lógica práctica: las decisiones que va tomando el hablante, se sustentan en su experiencia gramatical previa, que se concreta en habilidades adquiridas desde el proceso de socialización en su tierna infancia, como saber reconocer objetos, personas y nociones, usando diversas estrategias para ello. Que tiene que saber seleccionar y usar en su contexto. Y esos son los sentidos institucionalizados, su punto de partida, pero el hablante tiene que tomar en consideración a su contraparte en el diálogo y por lo tanto variar la manera de hablar y adaptarse a lo que supone es el universo de sentido de su contraparte, si quiere que lo entiendan. Porque a pesar de que hablen el mismo lenguaje, las experiencias previas con su

$50 \quad$ Lengua y Sociedad. Revista de Lingüística Teórica y Aplicada 
lenguaje siempre serán un poco distintas. Y el resultado es que las decisiones son únicas, tomadas en situaciones particulares y con fines específicos.

La experiencia nos da reglas supuestas, el vocabulario y muchos giros idiomáticos, pero en la aplicación podemos variar los sentidos, siempre y cuando nuestra contraparte nos siga, porque la intercomprensión es la medida del éxito del uso del lenguaje, no el estar de acuerdo a la norma -la gramaticalidad. Que además nadie la tiene formulada. Y este sí es un cambio radical en la percepción de cómo funciona el lenguaje.

Entre las estrategias para identificar un objeto, acción o persona está el:

- Reconocimiento globalizado

- Dar un nombre en contextos interactivos: llamar al gato por su nombre, advertir con el nombre, llamar la atención sobre uno mismo

- Dar un nombre, siguiendo reglas específicas como nombres y apellidos

- Nomenclatura de parentesco (papá, mamá)

- Pronombres personales (yo)

- Demostrativos (este)

- Distinguir nombres personales de genéricos (Cármen/ mamá)

- Poner apodos (que suponen nombres)

- Comparar el todo y las partes con otros objetos;

- campo semántico estructurado

- Función (Platón)

- Definición según reglas (sustancia y accidente en Aristóteles)

- Esencia (ousia) y apariencia; contenido

- Afiliar un caso particular a uno genérico: la cría del león es un león, la hoja caída del árbol de mango es de mango, aunque no lo parezca por la forma

- Parentesco familiar (Wittgenstein)

- Similitud con modelo

- Enfocarse en una acepción entre varias opciones

- Pars pro toto (usar naranjas por cítricos)

- Introducción al uso de la noción

- Historia o arqueología de la noción

Y otros. 
La función de identificar de lo que hablamos es seguro una de las funciones principales del lenguaje y puede respaldarse en una explicación explícita y ser parte de una negociación con recursos establecidos, pero nada impide que se introduzcan recursos atados a circunstancias y propósitos específicos. Piensen en Einstein explicando las nociones básicas de la teoría de la relatividad, por ejemplo, en circunstancias totalmente anómalas, como a la velocidad de la luz.

Puedo usar «naranjas» enfocado en la especie, excluyendo a las tangerinas en cierto contexto que hace la diferencia irrelevante, o incluyéndolas en otros. Y puedo no estar seguro de lo uno o lo otro, porque no lo tomé en cuenta en muchas más ocasiones, sin que eso invalide mi pensamiento como impreciso. Puedo usar naranjas como representante de todos los cítricos (pars pro toto), y puedo usar «naranjas» como negación, en una acepción popular totalmente distinta. Si quisiera organizar un campo semántico tendré dificultades, porque no está establecido cuáles características pertenecen al grupo y cuales no son relevantes.

\section{La identidad en la filosofía de Heráclito}

El problema de la identificación tiene un trasfondo filosófico, porque en la tradición occidental los filósofos tenían la convicción de que las nociones tenían algo inmutable y que no se podían mutar unas en otras, de manera que ser y no ser resultaran siendo lo mismo. Y si el discurso de un pensador hacía sospechar eso, se le criticaba implacablemente como «sofista». Eso diferenciaba a los que se consideraban filósofos de los sofistas.

El dilema de Heráclito, que según Conrado Eggers parece haber dicho: «no nos bañamos en el mismo río dos veces» (Eggers 1978, 1986) lo resuelve Wittgenstein al notar que el criterio establecido con que se identifica los ríos no son sus aguas, sino el cauce. Igualmente, sucede con los seres humanos, que renuevan sus células y con los años cambian las células de sus cuerpos, pero el criterio con el que se les identifica es social, se les pone un nombre de acuerdo a un sistema cultural específico para dar nombres. El hecho que se le otorgue un nombre es universal, pero el método es cultural. El poner nombre es entonces uno de los criterios con los que se identifica a personas, que tienen una apariencia física individual reconocible, tienen una historia personal, recuerdan dónde dejaron algo y cómo se llaman, saben dar razón de sí mismos (nombre, dónde viven, familia), se manejan bien con las actividades mentales y se dice que tienen consciencia, de manera

52 Lengua y Sociedad. Revista de Lingüística Teórica y Aplicada 
que hay unos criterios lógicos para identificar personas, otros sociales como ser inteligentes y algunos culturales, profesionales y personales. De manera que en la filosofía del lenguaje la identidad de las cosas, especies y personas depende de los criterios con que se juzgan las cosas, es decir de las razones que tenemos para diferenciarlas, que son criterios públicos y controlables. Y no dependen de fenómenos interiores, del yo, de almas o de esencias.

Es muy común, obviamente que se interprete la identidad siguiendo la imagen que es la pepa de un fruto. Pero también hay pueblos como los desana del Río Vaupés de Colombia, que tienen la idea opuesta que la esencia es como la cáscara que sostiene al fruto, como nos cuenta Gerardo Reichel-Dolmatoff, y que esa cáscara son todos los acuerdos sociales que sostienen la identidad de las cosas y que se asocian con las costumbres que estableció su dios Sol, lo que les da estabilidad y permanencia. De manera que evaden el problema del esencialismo que sí afecta tanto al pensamiento y la filosofía europea.

El problema filosófico tiene que ver con la identidad interpretada como algo transversal y permanente en las especies. Aristóteles lo llama ousia, y lo define como eso que hace que algo sea eso mismo, y piensa que puede haber una ciencia que trate de las ousias [Aristóteles 1978 pág. 335]. Posteriormente los epicúreos le llaman esencia. Lo que trataban de evitar con esta idea era que las cosas pudieran convertirse unas en otras, que no tuvieran una existencia permanente, aunque obviamente sabían que se podían transformar, quemar, partir etc. De esa inconsistencia es que se acusaba a los sofistas, que podían aseverar que algo era y no era al mismo tiempo. Heráclito, que había sostenido que «no nos bañamos en el mismo río dos veces», que se interpreta como la posibilidad de cambios constantes y que ser y no ser sea lo mismo. 


\section{Referencias bibliográficas}

Aristóteles (1978) Metafísica. Traducción directa del griego, Introducción, Exposiciones Sistemáticas e Índices de Hernán Zucchi. Buenos Aires: Editorial Sudamericana

Eggers Lan, C. $(1978,1986)$. Los filósofos presocráticos, Tomo I, II y III; Tomo I: Introducción general por Conrado Eggers Lan, introducciones, traducciones y notas por Conrado Eggers Lan y Victoria E. Juliá.; Tomo II. Introducciones, traducciones y notas por Néstor Luis Cordero, Francisco José Oliveri, Ernesto La Croce y Conrado Eggers Lan; Tomo II introducciones, traducciones y notas por Armando Poratti, Conrado Eggers Lan, María Isabel Santa Cruz de Prunes y Néstor Luis Cordero.: Madrid: Editorial Gredos

Hegel, G. W. F. (1965) System der Philosophie. In:Sämtliche Werke. Jubiläumsasugabe in zwanzig Bänden. Stuttgart-Bad Cannstatt: Friedrich Fromann Verlag,

Helberg Chávez, H. (1984) Zur Logik von $<$ Geist $>$ und $<$ Geistern $>$. En: Navicula Tubengensis. Studia in honorem Antonii Tovar. Editor: Francisco J. Oroz Arizcuren, con la colaboración de Eugenio Coseriu y Carlo de Simone. Tübingen: Gunter Narr

Helberg Chávez, H. (1996) Mbaisik... en la penumbra del atardecer. Literatura oral del pueblo harakmbut. Lima: CAAAP

Helberg Chávez, H. (2014) Interkulturelle Epistemologie, CONCORDIA - International Review of Philosophy, University of Aachen, Germany - oo 64, 2014

Helberg Chávez, H. (2017) Conocimiento intercultural - Indicaciones metodológicas. Lima, suR

Helberg Chávez, H. (2020) Filosofía intercultural de la experiencia cotidiana. Lima Grupo editorial Colónida. En Amazon

Marx, K. (1962,1963,1985) Das Kapital, Kritik del politischen Ökonomie. MEw Tomos 23, 24 y 25, Berlin: Dietz Verlag

Miró Quesada Cantuarias, F. 1982 Nuestra lógica, Revista Sudamericana de Filosofía, III,1, pp. 3-13-16

Newton, I. (1993, 1687): Principios matemáticos de la Filosofía natural [Philosophiae Naturalis Principia Mathematica]. Ediciones Altaya, S.A. Grandes Obras del Pensamiento, 21. 621 págs. Barcelona, ISBN 84-487-0140-2 [Estudio preliminar y traducción Antonio Escohotado]

Lao zi $(1978,1994)$ [el libro del Tao] Traducción, prólogo y notas de Juan Ignacio Preciado. Edición bilingüe.

54 Lengua y Sociedad. Revista de Lingüística Teórica y Aplicada 
Palau, G. (2014). Lógica formal y argumentación como disciplinas complementarias. (Biblioteca Humanidades, 35). La Plata: Universidad Nacional de La Plata, Facultad de Humanidades y Ciencias de la Educación (UNLP - FaHCE). https://nbn-resolving.org/urn:nbn:de:0168-ssoar-432730

Reichel-Dolmatoff, G. (1975) The Jaguar and the Shaman: A Study of Narcotic Drugs among the Indians of Colombia. Prólogo de Richard Evans Schultes. Philadelphia: Temple University Press

Wittgenstein, L. (1970) Über Gewißheit. Editado por G.E.M. Anscombe y G.H. von Wright. Frankfurt a.M.: Suhrkamp Verlag

Wittgenstein, Ludwig (2001) Philosophische Untersuchungen. Kritisch-genetische Edition. Herausgegeben von Joachim Schulte in Zusammenarbeit mit Heikki Nyman, Eike von Savigny und Georg Henrik von Wright. Frankfurt am Main: Suhrkamp Verlag

Zhuang zi (2020) En: Internet Encyclopedia of Philosophy https://iep.utm.edu/ zhuangzi/, visto el 25/10/2020 